Original Research Paper

\title{
Method of Efficiency Improvement in District Heating Systems
}

\author{
Andrey Gennadiievich Batuhtin, Maxim Stanislavovich Bass, Sergey Anatoljevich Ivanov, \\ Sergey Gennadiievich Batuhtin and Pavel Grigiorjevich Safronov
}

Faculty of Energy, "Thermal Power Plants" Transbaikal State University, Chita, Russian Federation, Russia

\author{
Article history \\ Received: 07-10-2015 \\ Revised: 17-01-2016 \\ Accepted: 29-01-2016 \\ Corresponding Author: \\ Maxim Stanislavovich Bass \\ Faculty of Energy, "Thermal \\ Power Plants" Transbaikal \\ State University, Chita, \\ Russian Federation, Russia
}

Tel: 7-302-241-7085

Email: monblan.pro@yandex.ru

\begin{abstract}
The article determines application potential of solar energy in conditions of sharply continental climate. It presents an energy-efficient solar energy recovery scheme in district heating systems, allowing to reduce capital costs and maintenance charges and to increase degree of substitution of conventional sources of heat. Versatility of systems using this method results in its multi-zone application: From a cottage-type house to heating of industrial premises and green house complexes. The main principle of the suggested method is in connection of a solar collector via heated medium to an air conduit, which is connected with heated space and antifreeze, circulating in-line: Reservoir-accumulator-solar collector. A method of heat transfer enhancement using dimple-type intensifiers is suggested. The article determines enhancement efficiency via calculation of daily heat-absorption of a flat air collector with and without dimple intensifiers, as well as economic effect from introducing of the suggested method. According to calculations, the adoption of the suggested heating system and heat transfer enhancement on the surface of the collector connecting to it, may give a perceptible economic effect.
\end{abstract}

Keywords: Nonconventional Energy Sources, Solar Plants, Power Supply, Solar Energy

\section{Introduction}

The climate of the biggest part of the territory of Russia can be defined as continental. Nevertheless, its considerable part is located in the zones of sharply continental climate. The average value of the degree-day index (sum of average monthly temperature differences of internal and external air for a heating period (Batukhtin, 2014; 2013; Semyonov, 2002 ) is $5000^{\circ} \mathrm{C} \cdot$ day for Russia, that is almost twice as much as in Denmark and the USA (Batukhtin et al., 2015a). This value is higher than the value for the most northern European country-Sweden $\left(4017^{\circ} \mathrm{C} \cdot\right.$ day) (EDD, 1993). However, integral characteristic of Siberia regions with sharply continental climate is higher and achieves $12045^{\circ} \mathrm{C} \cdot$ day for Oimyakon (Semyonov, 2002).

Strategic target of the state energy policy in the sphere of a balanced fuel and energy budget developing is to optimize generation plan, domestic consumption and export of fuel and energy resources with due regard to energy security, economic and energy efficiency requirements and strengthening of foreign economic positions of the country. Furthermore, the first place in its implementation in
"Energy strategy of Russia for the period until 2030" takes the extension of importance of renewable energy sources in satisfying the energy requirements of the society. Without the adoption of technologies, allowing to force out fossil fuel from the fuel balance of the country, it is impossible to implement basic principles of the strategy, foreseeing the most efficient use of natural energy resources and energy industry potential for the stable growth of economy and improvement of the quality of life of the population of the country (Dostovalova et al., 2014; Goryachikh et al., 2010; Bass and Batukhtin, 2011). Solar energy (Batukhtin et al., 2015b) is the most productive among renewable energy sources for the majority of Russian regions, except regions with wind load parameters sufficient for giving specified rates to wind turbines (10$16 \mathrm{~m} \mathrm{sec}^{-1}$ (Li and Zhe Chen, 2008)).

\section{Materials and Methods}

At the present time a considerable amount of different methods of solar energy usage in hot water supply and hot water heating systems have been 
developed. Space heating by warm air on the basis of heat sources of different types allows in many cases to considerably reduce capital costs and maintenance charges. The usage of solar heating with solar collectors of different type in warm-air heating systems will allow increasing considerably the efficiency of these systems and will raise the degree of substitution of conventional sources of heat. Water or air, depending on the temperature mode, is heated in these systems, or water and air are heated conjointly: For hot water supply and for heating systems respectively. Since our final objective is indoor air heating, these systems precisely allow reaching maximum efficiency, excluding all interstage processes and transformations. As a heating source, heat from burning fuel as well as heat received from solar collectors could be used (Batukhtin and Batukhtin, 2009).

Air collectors are used in Canada, in most similar to Russian conditions. At present time the most efficient constructions of flat solar collectors are designed by Conserval Engineering Inc. together with several scientific centers of Canada. Mid-annual efficiency of their best models is: Coefficient of efficiency $=35-60 \%$ (SolarWall, 2008), under quite low heat transfer coefficients (Alam et al., 2014; Smith et al., 2012; Thianpong et al., 2012). The leader of solar heating of air at Asian market is "Himin" company, which uses vacuum capillary heat pipes for air heating (national patent 1 NO. 200820123062.7). These circuit designs have not become widely used due to low efficiency values (passport average-heating coefficient of efficiency- 50\%; mid-annual-lower than 30\%) at high cost. Air-and-water solar collectors have been recently designed with mid-annual coefficient of efficiency of solar energy conversion more than $65 \%$, due to advantages of heat-exchange and heat-conductive fluids usage and, consequently, a year-round radiant heat absorbing surface (Patent RF №2403511). Versatility of systems results in its multi-zone applications: From a cottage-type house to heating of gigantic industrial premises and green house complexes. The majority of advantages of this method may become possible only while using non-freezing liquids in solar collectors. Air heating can be made in both: In intermediate heat exchanger from the liquid heated in the collector and directly in the collector. Technical-economic assessment of solar collectors' usage in heating systems showed that for the conditions of Zabaykalsky Krai the payback period falls within the range 9-11 years. The highest value corresponds to the lowest heating load of a building (Batukhtin et al., 2015a). 2014):

Advantages of air heating are (Dostovalova et al.,

- Economical efficiency. As heat is produced directly in the hated space
- Improving conditions of stay in the premises, as heating of air by $40-70^{\circ} \mathrm{C}$ is quite sufficient for forced ventilation

- Fast response, as hot-air heating system allows full warming of the premises in 1.5-2 $\mathrm{h}$

- No intermediate heat-transfer medium, that allows freedom from hot-water heating system construction. In winter time the risk of system defrosting is excluded

- High-degree automation allows generating heat directly on demand

The majority of advantages of this method may be possible only when using non-freezing liquids in solar collectors. Air heating can be made in both: Intermediate heat exchanger from the liquid heated in the collector and directly in the collector. Figure 1 shows the recovery scheme of solar energy, enabling to combine these methods (Patent RF№2403511).

The usage of this scheme will allow using the advantages of air-type heating systems with adoption of solar collectors of combined type (with joint heating of air and heat-conductive fluid), as well as reducing the temperature of a rays receiving plate and, consequently, radiating loss. Figure 1 shows connection circuit and operation mode of the solar plant.

For the most efficient usage of solar collectors' capacity, it is suggested to heat tap water after the first stage of the heater of hot water supply and, if necessary, to warm it up again in the upper stage, fitted with temperature automatic control system. For smoothing of daily irregularities of solar radiation access it is suggested to use an accumulator box, fitted with integrated heat exchangers.

The technical result of the invention is efficiency improvement of solar plant functioning via solar energy transfer using the solar plant in the air heating and hot water supply system.

The application method is that cold air, having passed the solar collector, comes to an air conduit, wherein the heating surface is integrated and is connected via heating medium to the circuit with antifreeze, the heating surface is also connected to accumulator box via heating medium. When solar radiation is sufficient, the heated anti-freeze liquid in a solar collector is send out by a three-way valve into two flows: One flow of anti-freeze comes to the heating surface, after air heating antifreeze is mixed with the second flow and is directed into the accumulator box, where anti-freeze is cooled by giving its heat to water. After the cooling, anti-freeze is conducted to the solar collector via a circulating pump and the cycle repeats. When solar radiation is insufficient, anti-freeze is not conducted into the heating surface, but to the accumulator box. When there is no solar radiation or when solar radiation is very low, the circulating pump is stopped. 


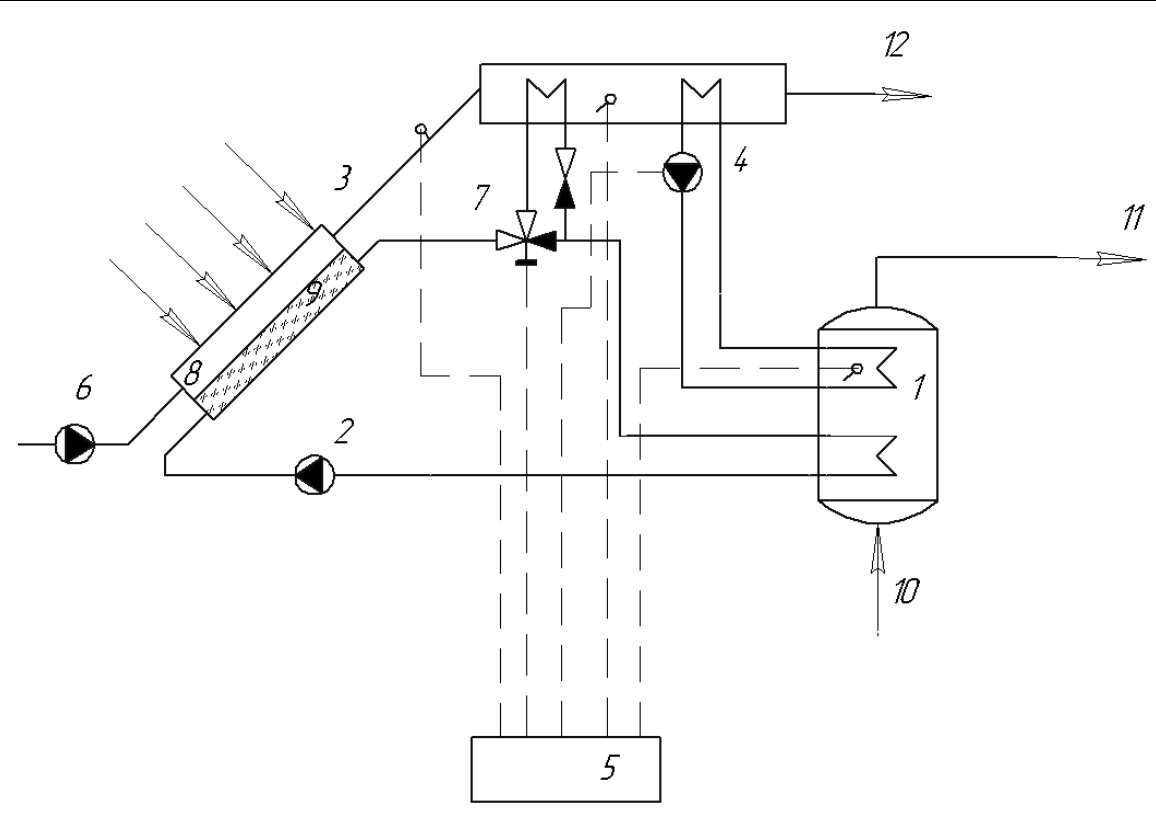

Fig. 1. Air-and-solar heating system: 1- Accumulator box; 2- Solar circuit pump; 3- Air-and-solar collector; 4- Calorifier; 5Automatic control system; 6- Inlet air ventilator; 7- Three-way valve of a solar circuit; 8- Air heating space; 9- Rays receiving plate; 10- Cold water; 11- Heated water; 12- Air to the heating system

Cold water, coming into the accumulator box, is heated by an external source of heat and by anti-freeze, which deliver heat through heating surfaces. After the heating, water is directed to consumers. When there is no solar radiation, air in air conduits is heated by the heating surface, in this surface both water and anti-freeze may be used as heat carrier medium, when using water the circulating pump may be turned on only at positive temperatures of outdoor air. When using anti-freeze, this circuit may be turned off and air heating supply is stopped. Heat medium temperature regulation is provided by automatic control system, its input signal is temperature detecting data.

For implementation of circuitry of energy efficient air-and-solar heating plant, it is required to design a special-purpose solar collector. The distinguishing feature of this heat exchanger is the possibility of simultaneous heating of two types of heat carriers.

The circuit efficiency is determined by the maximum, compared with the others, performance in different seasons:

- In winter season, as opposed to the pure water systems, the air part of solar collector has a maximum efficiency

- In summer season, as opposed to pure air systems (not operating), domestic hot water heating (water part) has the maximum efficiency

- In the transitional seasons combined operation of air-and-solar heating and DHW heating maximizes the efficiency of the solar collector
The efficiency of the collector (Fig. 1) may be increased considerably by heat-exchange enhancement on surfaces with hemispherical dimples due to extension of heat exchange space.

The work (Kiknadze and Olennikov, 1990) studied a new class of quasi-potential swirling gas and liquid flows, which forming is realized either due to confluence of purposely directed flows of working continuous medium or during flow-around of its three-dimensional dimples (so-called "vortex generators") on energyexchanged or supporting surfaces.

High-performance practical use of these flows became possible due to a large-scale thermodynamic research and experimental development. Thus, according to experimental data, fluxes of vorticity, formed in accordance with accurate solutions of hydrodynamic equations, double gas and liquid flow in comparison with flows of a different nature in pipes of equal size and form. These swirling flows selforganize in heat carrier flows, flowing around heatexchange surfaces, formed by special "vortex generator" shapes (Kiknadze and Olennikov, 1990), significantly intensify the heat and mass exchange at decreasing aerodynamic resistance of energyexchanged ducts.

Hemispherical design of dimples (holes) on the solarreceiving surface of the collector and on the internal and external surfaces of ducts, transporting liquid heat carrier medium, considerably intensify the heat-exchange and decrease aero-hydrodynamic resistance in energyexchanged ducts due to vortex over spherical dimples, 
forming stable swirling flow of gas and liquid fluids, perpendicular to the moving direction of the basic weight of continuous medium.

In this case, the solar collector functions in the following way. Solar radiation, having passed through the glass, is heating absorber, which in its turn is heating the gaseous medium (air), going through the gas-heating chamber 8 , while hemispherical dimples on the solar-receiving surface 9 will stimulate considerable heat-exchange enhancement. Liquid heat carrier medium in the solar collector is circulating in a harp-shaped pipe system and as they are submerged into a solar-receiving plate by $50 \%$, they will be heated and hemispherical dimples on the internal side of ducts will also stimulate heat-exchange enhancement.

Technological characteristics of manufacturing of this collector may be adopted by analogy with production methods of enhanced heating surfaces of boiler equipment heating at production enterprise Belgorod energy engineering plant (PE «Belnergomash-BZEM»). Turbulent Enhancement of Heat and Mass Exchange (EHME) in these ducts is achieved by different methods, for instance, by stamping from one or both sides of the strap, welded after that to a duct by specialized equipment. Achieved increase of heat transfer coefficient allows in this case economizing $30 \%$ of metal during manufacturing of heat-exchange points. Another design solution, improving boiler characteristics, is insertions of a formed strap. The most important method of turbulent EHME is imposing of threedimensional incurvity of dimples directly on the heatexchanging surface of ducts. This is achieved by cages with punches, rolling cages and dies.

Efficiency improvement of heat-exchange in the designed collector is determined by local growth of heattransfer coefficient and extension of space. The growth of heat-transfer coefficient may be defined on the basis of experimental data or by calculation.

The work (Sapozhnikov et al., 2012) makes an assessment of forced convective heat-exchange enhancement by spherical dimples with similar sizes by numerical simulation and experimental gradient heatmeasurement.

Optimality of choice of the spherical dimples form for heat-exchange enhancement in the designed collector is proved (Sapozhnikov et al., 2012). Comparison of experimental data shows that the peak enhancement for numbers $\mathrm{Re}>3 * 10^{4}$ is common for spherical intensifiers.

Calculation of daily heat absorption of a flat air-andwater collector with and without enhancement by dimples was made to define enhancement efficiency (using (State registration certificate for computer program №2009614238)):

- Climatological data: Chita: Longitude- 113 h 23 min, latitude- 52 h 6 min, date October $1^{\text {st }} 2013$

- Surface guidance: Attitude angle to horizon- 45 degree, azimuth direction $180^{\circ} \mathrm{C}$

- Plate: Measures of the plate are stated: $1000 * 100 * 10$ $\mathrm{mm}$, material-copper, wall thickness $2 \mathrm{~mm}$

- Ducts: Quantity 10 pcs, diameter $25 \mathrm{~mm}$, materialcopper, wall thickness $1 \mathrm{~mm}$, proportion of range $50 \%$, material of thermos-interface-stannum, layer thickness 500 micron.

- Absorbent: Coloring-matted black paint (degree of absorption 95, blackness 5, selectivity 0.4 )

- External insulation: Glass-two layers, thickness 1 $\mathrm{mm}$, attenuation coefficient $0.41 / \mathrm{mm}$, size of air passage $30 \mathrm{~mm}$

- Air conditions: input air temperature $0^{\circ} \mathrm{C}$, air flow rate- $1000 \mathrm{~m}^{3} / \mathrm{h}$

While calculating daily heat absorption of a regenerative air-and-water heat-exchanger with advance heat-exchange efficiency, heat-transfer coefficients, obtained by standard method, are increased in proportion to average (by the surface of a dimple) relative heat-transfer coefficients. For the record of extension of heat-exchange space it is required to measure its relative increase $K_{F}$ and take it into account in the standard method.

For suggested geometrical parameters of hemispherical dimples, $K_{F}$ takes on values from 1.09 to 1.116 , depending on the packing density (for preliminary assessment in calculations $K_{F}=1,1$ ). The calculations made showed that the flow regime is turbulent: $\operatorname{Re}=696364$. For this regime we take (Fig. 2 ((Sapozhnikov et al., 2012)) $\bar{\alpha}=1.25$ during enhancement on spherical intensifiers.

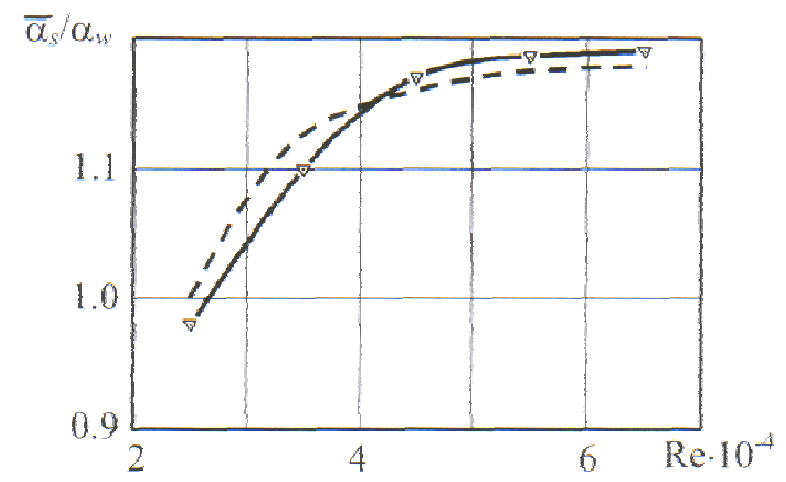

Fig. 2. Average (by the surface of a dimple) relative heattransfer coefficients for a spherical dimple (Sapozhnikov, 2012) 
Table 1. Results of calculation for a flat collector (input air temperature $=$ environmental temperature $=0{ }^{\circ} \mathrm{C}$ )

\begin{tabular}{lllc}
\hline & Local time & \multicolumn{2}{l}{$\begin{array}{l}\text { Heat absorbed by the collector } \\
\text { (without enhancement), W: }\end{array}$} \\
№ in order & 1. & 2. & $\begin{array}{l}\text { Heat absorbed by the collector } \\
\text { (enhancement: } K_{F}=1.1, \bar{\alpha}=1.25 \text { ), W: }\end{array}$ \\
\hline 1. & $9: 00$ & 0 & 3. \\
2. & $10: 00$ & 150 & 152 \\
3. & $11: 00$ & 362 & 377 \\
4. & $12: 00$ & 550 & 590 \\
5. & $13: 00$ & 625 & 635 \\
6. & $14: 00$ & 670 & 675 \\
7. & $15: 00$ & 655 & 660 \\
8. & $16: 00$ & 585 & 595 \\
9. & $17: 00$ & 455 & 465 \\
10. & $18: 00$ & 260 & 267 \\
11. & $19: 00$ & 50 & 52 \\
12. & $20: 00$ & 0 & 0 \\
13. & Total & 4362 & 4468 \\
\hline
\end{tabular}

\section{Results and Discussion}

The results of calculation and experimental studies of daily heat absorption of a flat air-and-water collector are presented in the Table 1.

Enhancement showed $2.43 \% \quad$ efficiency improvement. Annual enhancement efficiency, calculated using (State registration certificate for computer program No. 2009614238) and in accordance with methods (Batukhtin et al., 2015a; Batukhtin, 2014; Batukhtin, et al., 2014; Batukhtin and Pinigin, 2012; Batukhtin et al., 2012; Bass et al., 2012; Pinigin and Batukhtin, 2012; Kirillov et al., 2013; Batukhtin and Kobylkin, 2013; Bass et al., 2013; Goryachikh and Batukhtin, 2013; Batukhtin et al., 2013; Pinigin and Batukhtin, 2015; Batukhtin et al., 2015b) for a circuitwise collector (Fig. 1 (Patent RF №2403511)), will be $106 \mathrm{~kW} / \mathrm{m}^{2}$.

To confirm the efficiency of the design values experimental study of the intensification effect was carried out (in the period from September 1, 2015 to November 1, 2015). The actual increase in the amount of useful heat made $35 \mathrm{~kW} / \mathrm{m}^{2}$.

Taking present tariff rate in district heating system in Chita $1925 \mathrm{rub} / \mathrm{Gcal}$, economic benefit is $175,5 \mathrm{rub} / \mathrm{m}^{2}$.

Such intensification and economic benefits can be obtained without significant increase in the cost of solar collectors manufacturing, since the implementation of hemispheric intensifiers can be accomplished in a single process operation. At the same time there is no increase in operating costs.

\section{Conclusion}

- Cost-effectiveness analysis showed considerable economic benefit from adoption of suggested methods

- The considered method of heat transfer intensification is technologically simple to produce; it does not require expensive materials and assumes no additional operating costs

- $\quad$ The proposed scheme allows accumulating thermal energy in the water tank accumulator and to use it in the absence of solar radiation both for water heating for domestic hot water supply and for air heating

- The disadvantages of the circuit include the complexity the control system and the presence of additional elements and heat exchange equipment

The article reviews application potential of different types of renewable energy sources in conditions of sharply continental climate. The following types can be classified as main types of renewable energy sources in the described conditions (Batukhtin et al., 2014):

- Geothermal energy

- Biomass energy

- Hydraulic power (mini-HPP)

- Wind energy

- Solar energy

Usage of solar energy is considered to be most practical for heating supply needs. The article reviews application potential of solar energy use in conditions of sharply continental climate of Russia. Energyefficient scheme of solar energy use in district heating systems has been presented, allowing to reduce capital costs and maintenance charges and to increase degree of substitution of conventional sources of heat. Versatility of systems using this method results in its multi-zone application: From a cottage-type house to heating of industrial premises and green house complexes. The main principle of the suggested method is in connection of a solar collector via heated medium to an air conduit, which is connected with heated space and antifreeze, circulating in-line: Reservoir-accumulator-solar collector. Methods of 
heat-exchange enhancement have been presented. A method of heat transfer enhancement using dimpletype intensifiers has been suggested. Enhancement efficiency via calculation of daily heat-absorption of a flat air collector with enhancement with and without dimple intensifiers and economic effect from introducing of the suggested method have been determined. According to calculations, the adoption of the suggested heating system and heat transfer enhancement on the surface of the collector connecting to it, may give a perceptible economic effect.

\section{Acknowledgement}

The authors thank Transbaikal State University for supporing this research.

\section{Funding Information}

This article was funded by the Energy Faculty, "Thermal power plants" Transbaikal State University,

\section{Author's Contributions}

Andrey Batuhtin: Designed the research plan, participated in the results analysis, contributed to the reviewing of the article critically.

Maxim Stanislavovich Bass and Sergey Anatoljevich Ivanov: Organized the study, data collection of the study sample, analysis and writing of the manuscript.

Sergey Gennadiievich Batuhtin and Pavel Grigiorjevich Safronov: Contributed in development of the conceptual framework, results analysis, drafting of the article.

\section{Ethics}

The authors have no conflicts of interest in the development and publication of current research.

\section{References}

Alam, T., R.P. Saini and J.S. Saini, 2014. Heat and flow characteristics of air heater ducts provided with turbulators-A review. Renewable Sustainable Energy Rev., 31: 289-304. DOI: 10.1016/j.rser.2013.11.050

Bass, M.S. and A.G. Batukhtin, 2011. An integrated approach for optimizing the operation of modern heat supply systems. Thermal Eng., 58: 678-681. DOI: $10.1134 / \mathrm{S} 0040601511080052$

Bass, M.S., A.G. Batukhtin and S.A. Trebunskikh, 2013. Methodical problems of efficiency analysis of district heating systems. Scientific and Technical Reports of SPbSTU.
Bass, M.S., A.G. Batukhtin and S.G. Batukhtin, 2012. Optimization method of equipment configuration in compound heat supply systems. Indust. Energet., 10: 49-52.

Batukhtin, A., P. Safronov and M. Kirillov, 2014. Improving the efficiency of fuel combustion in boilers with windmills-fans on the example of kharanorskaya SDPT. Middle-East J. Scientific Res., 21: 487-490.

DOI: 10.5829/idosi.mejsr.2014.21.03.21431

Batukhtin, A.G., 2014. A technical and economic feasibility study on the choice of solar collector power output in compound heat supply systems. World Applied Sci. J., 31: 542-547. DOI: 10.5829/idosi.wasj.2014.31.04.14320

Batukhtin, A.G., V.V. Pinigin and M.V. Kobylkin, 2012. Analysis of efficiency improvement methods in district heating systems. Scientific and Technical Reports of SPbSTU.

Batukhtin, A.G. and M.V. Kobylkin, 2013. Automatic flow control system of coolant flow for consumer group heat supply. Scientific and Technical Reports of SPbSTU.

Batukhtin, A.G., 2013. Development of criteria and methods of district heating systems improvement, functioning in conditions of sharply continental climate: Monograph. ZabGU, Chita.

Batukhtin, A.G., S.A. Ivanov, M.V. Kobylkin and A.V. Mitkus, 2013. Improving the efficiency of modern heat supply systems. Transbaikal State Univ. J., 9: 112-120.

Batukhtin, A.G. and V.V. Pinigin, 2012. Mode optimization of heat-radiating equipment using natural zeolites for reducing polluting emissions. Chita State Technical Univ. J., 7: 19-24.

Batukhtin, A.G., 2014. Modern methods of district heating systems improvement: Monograph. ZabGU, Chita.

Batukhtin, A.G., S.A. Ivanov and M.V. Kobylkin, 2015a. The use of water heat pump systems with nonconventional source of low-grade energy for load compensation of hot water supply. Indust. Energet., 3: 18-21.

Batukhtin, A.G., M.S. Bass and S.G. Batukhtin, 2015b. Optimization for the equipment in combined heating systems. Modern Applied Sci., 9: 93-93.

Batukhtin, A.G. and S.G. Batukhtin, 2009. Modern methods of efficiency improvement in combined action of solar heating plants and district heating systems. Scientific Techn. Rep. SPbSTU, 3: 48-53.

EDD, 1993. Decentralized combined heat and power production in Denmark. Publ. Energy Departments of Denmark, Copenhagen, pp: 56. 
Dostovalova, S.S., R.A. Serebryakov, S.G. Batukhtin and A.G. Batukhtin, 2014. Regenerative air-andwater heat exchanger with advanced heat transfer efficiency. Samara State Aerospace Univ. J., 4: 61-66.

Goryachikh, N.V. and A.G. Batukhtin, 2013. The use of factor analysis for mode operation optimization of heat supply systems. Industr. Energet., 9: 26-30.

Goryachikh, N.V., A.G. Batukhtin and S.A. Ivanov, 2010. Some methods for making cogeneration stations more maneuverable. Thermal Eng., 57: 892-896.

Kiknadze, G.I. and V.G. Olennikov, 1990. Selforganization of turbulent-like swirling structures in gas and liquid flows and heat and mass transfer enhancement. Preprint of Institute of Thermophysics SD AS USSR-Novosibirsk.

Kirillov, M.V., P.G. Safronov and A.G. Batukhtin, 2013. Efficiency calculation method for rate-of-turn transducers of engines in CHP centrifugal pumps. Indust. Energet., 1: 17-20.

Li, H. and Z. Chen, 2008. Overview of different wind generator systems and their comparisons. IET Renewable Power Generat., 2: 123-138.
Pinigin, V.V. and A.G. Batukhtin, 2015. Exergy analysis of reduction methods of polluting emissions from CHP boilers. Indust. Energet., 2: 50-54.

Pinigin, V.V. and A.G. Batukhtin, 2012. Reagent methods optimization of polluting emissions from CHP boilers. Indust. Energet., 12: 46-49.

Sapozhnikov, S.Z., V.Y. Mityakov and A.V. Mityakov, 2012. Basics of Gradient Thermometrology. 1st Edn., Publ. of Politech. Instit, Saint Petersburg, pp: 203.

Semyonov, B.A., 2002. Optimization of heat-usage systems in district heating systems. PhD Thesis. SGTU, Saratov.

Smith, E., N. Koolnapadol and P. Promvonge, 2012. Heat transfer behavior in a square duct with tandem wire coil element insert. Chin. J. Chem. Eng., 20: 863-9.

SolarWall, 2008. SolarWall. http://www.solarwall.com Thianpong, C., K. Yongsiri, K. Nanan and S. Eiamsa-Ard, 2012. Thermal performance evaluation of heat exchangers fitted with twistedring turbulators. Int. Commun. Heat Mass. Transf., 39: 861-8. 